\title{
Optimal annuity portfolio under inflation risk
}

\section{Konicz, Agnieszka Karolina; Pisinger, David; Weissensteiner, Alex}

\section{Published in:}

Computational Management Science

Link to article, DOI:

$10.1007 / \mathrm{s} 10287-015-0234-1$

Publication date:

2015

Link back to DTU Orbit

Citation (APA):

Konicz, A. K., Pisinger, D., \& Weissensteiner, A. (2015). Optimal annuity portfolio under inflation risk. Computational Management Science, 12(3), 461-488. https://doi.org/10.1007/s10287-015-0234-1

\section{General rights}

Copyright and moral rights for the publications made accessible in the public portal are retained by the authors and/or other copyright owners and it is a condition of accessing publications that users recognise and abide by the legal requirements associated with these rights.

- Users may download and print one copy of any publication from the public portal for the purpose of private study or research.

- You may not further distribute the material or use it for any profit-making activity or commercial gain

- You may freely distribute the URL identifying the publication in the public portal

If you believe that this document breaches copyright please contact us providing details, and we will remove access to the work immediately and investigate your claim 


\section{Optimal annuity portfolio under inflation risk}

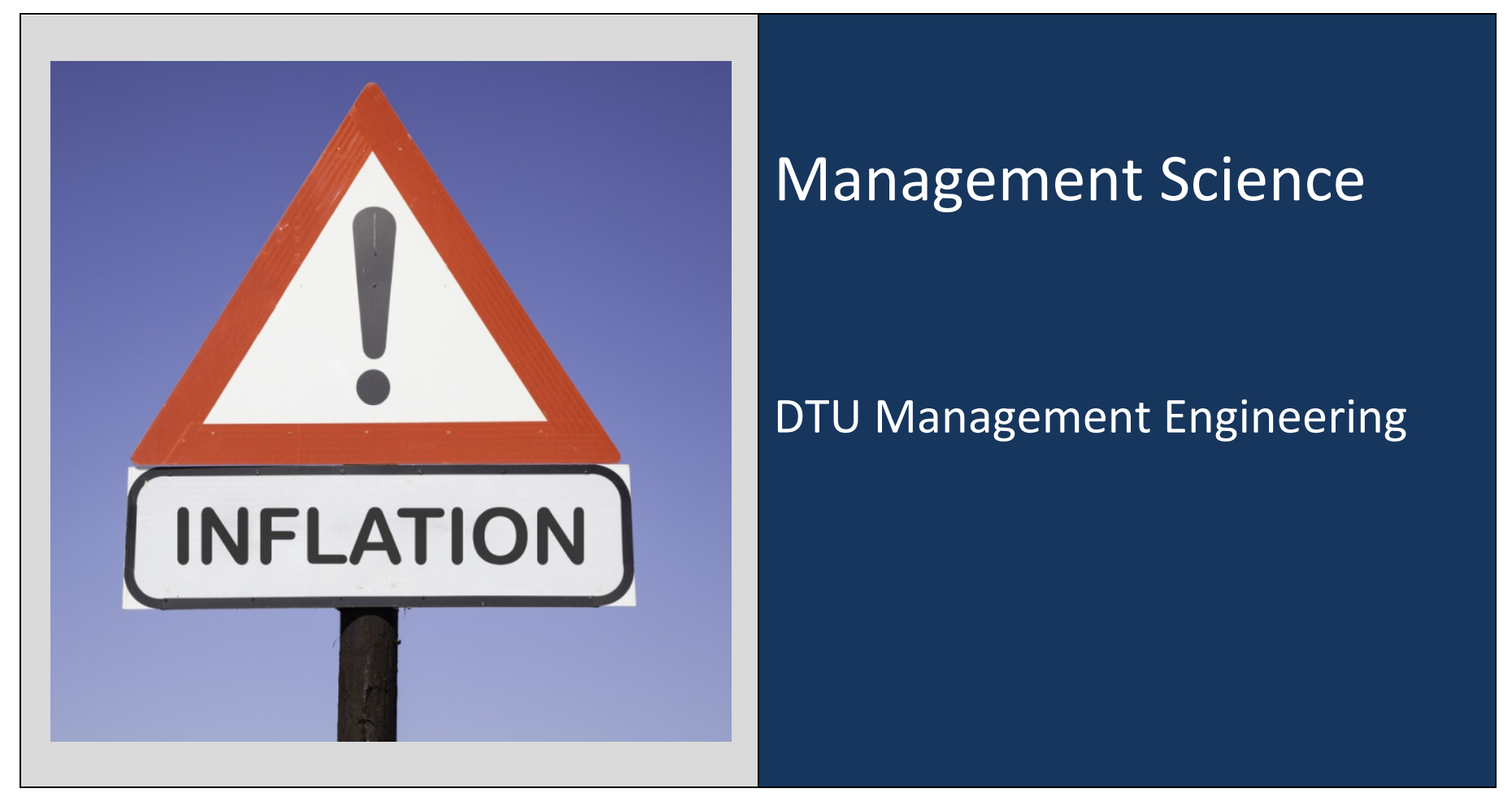

Agnieszka Karolina Konicz

David Pisinger

Alex Weissensteiner

September 2014 


\title{
Optimal annuity portfolio under inflation risk
}

\author{
Agnieszka Karolina Konicz* \\ agko@dtu.dk \\ David Pisinger \\ dapi@dtu.dk
Alex Weissensteiner
alwe@dtu.dk

DTU Management Engineering, Management Science, Technical University of Denmark

September 5, 2014

\begin{abstract}
The paper investigates the importance of inflation-linked annuities to individuals facing inflation risk. Given the investment opportunities in nominal, real, and variable annuities, as well as cash and stocks, we investigate the consumption and investment decisions under two different objective functions: 1) maximization of the expected CRRA utility function, and 2) minimization of squared deviations from an inflation-adjusted target. To find the optimal decisions we apply a multi-stage stochastic programming approach. Our findings indicate that independently of the considered objective function and risk aversion, real annuities are a crucial asset in every portfolio. In addition, without investing in real annuities, the retiree has to rebalance the portfolio more frequently, and still obtains the lower and more volatile real consumption.
\end{abstract}

\section{JEL classification: C44 • D14 $\bullet \mathrm{D} 91 \bullet \mathrm{G} 11 \bullet \mathrm{G} 23 \bullet \mathrm{J} 26$}

Keywords: Inflation-linked annuity $\bullet$ Retirement planning $\bullet$ CRRA utility $\bullet$ Loss disutility $\bullet$ Multi-stage stochastic programming

\section{Introduction}

When planning for retirement, individuals often decide to purchase nominal annuities that guarantee fixed income no matter how long one lives. However, what they tend to forget is that these products expose them to substantial uncertainty around the real value of their income. In the event of high inflation, the purchasing power of income may not be sufficient to cover standard living costs.

To accommodate the individuals' needs, during the last decades a new type of financial products became available in the market; namely, inflation-linked (real) annuities. The income provided by these products increases each year with the Retail Price Index (RPI) or Consumer Price Index (CPI) measuring inflation, thus gives the annuitants a natural protection against inflation. As investigated in Brown et al. (2000, 2001), real annuities are available at least in the British and American market, and are offered especially by private insurers.

Many scholars have investigated the demand for the inflation-linked products, mostly in the expected utility maximization framework, see, e.g. Fischer (1975), Brown et al. (2001), Campbell and Viceira (2001), Brennan and Xia (2002), Soares and Warshawsky (2003), Koijen et al. (2011), Han and Hung

\footnotetext{
* Corresponding author at: DTU Management Engineering, Management Science, Technical University of Denmark, Produktionstorvet 426, 2800 Kgs. Lyngby, Denmark. Tel.: +45 4525 3109; Fax: +45 4525 3435; email: agko@dtu.dk
} 
(2012) and Kwak and Lim (2014). These studies have shown that the existence and availability of inflation-linked assets are desirable for individuals. Moreover, Fischer (1975) and Kwak and Lim (2014) argue that the demand for inflation-linked bonds increases with a decline in the correlation between stocks and inflation rate; Soares and Warshawsky (2003) argue that the prices of inflation-linked annuities over time are much less volatile than the prices of nominal fixed and increasing annuities; whereas Campbell and Viceira (2001), Koijen et al. (2011) and Han and Hung (2012) show that inflation-linked products are most beneficial for conservative investors. In addition, Koijen et al. (2011) argue that in the presence of real annuities, independently of the risk aversion level, individuals allocate only a marginal amount to nominal annuities, whereas Kwak and Lim (2014) prove that inflation-linked bonds are not only a perfect hedge for inflation risk, but also serve as investment opportunity and portfolio diversification.

Despite these scientific findings in favour of inflation-linked products, as recently investigated in the UK, about 95\% of retirees do not purchase inflation-linked annuities, see Cowie (2011) and Towler (2013). British pension experts explain that retirees' reluctance towards real annuities is related to the high price of these products; because insurers do not know how high inflation will be in the future, they price real annuities more conservatively than nominal annuities. Therefore, it may take many years before the payments from real annuities exceed those from nominal annuities with constant payments. To exemplify, Hyde (2013) shows that the initial income from inflation-linked annuities can even be $40 \%$ lower than from annuities with constant nominal payments. Given a realized inflation of $3 \%$ per year, a retiree would have to wait until age 82 before the lower payouts from the real annuities exceeded those from the nominal annuities with constant payments. Accordingly, given the lifetime expectancy of nearly 90 years, individuals find this waiting period too long, and prefer to take the risk of experiencing a severe shrinkage in their income.

On the other hand, retirees who are concerned about inflation risk, often prefer to invest in stocks. According to a common belief, stocks are a natural hedge against inflation; however, the empirical studies have reported a negative correlation between the stock returns and the inflation rate, see, e.g., Fama (1981), Geske and Roll (1983), Lee (1992), and Brown et al. (2001). Moreover, Attié and Roache (2009) shows that assets such as commodities, which are known to be an effective hedge against inflation in short-term investment strategies, may not work over longer horizons. Thus, retirees owning stocks or variable annuities (annuities whose income is linked to stock returns) should not feel certain about the real value of their income.

The purpose of this paper is twofold: 1) to investigate whether inflation-linked products are beneficial to individuals with different retirement goals, and 2) to investigate how the retirees can protect themselves against inflation risk without investing in real annuities. To support our argumentation, we suggest an optimization model whose solution provides recommendations regarding how to ensure the retirement income in real terms.

As the main goal of retirement planning is to make sure that the life-long income is sufficient to cover standard living costs independently of the level of inflation, we model the optimization problem under two different objective functions. The first objective is a maximization of the expected constant relative risk aversion (CRRA) utility of real consumption, as investigated e.g., in Brown et al. (2001) and Koijen et al. (2011). The second objective is a minimization of the expected disutility, defined by a quadratic loss function penalizing deviations from a certain inflation-linked target. Neither the quadratic disutility nor the target-based approach is new in the literature on retirement planning, see, e.g., Cairns (2000), Gerrard et al. (2004), Blake et al. (2013), and Di Giacinto et al. (2014), however, none of the studies considered inflation risk or the presence of inflation-linked products, and only Blake et al. (2013) allowed for a pathdependent target. When searching for the optimal investment and consumption decisions under both 
objective functions, we allow the individual to allocate his savings to nominal annuities with constant payments, inflation-linked annuities (RPI-adjusted), variable annuities and stocks (whose returns follow the MSCI UK stock index), or keep them on a bank account with floating interest rate.

The aforementioned studies typically focus on deriving an explicit solution to a given problem by using dynamic programming. However, solving a problem of wealth allocation to nominal, real and variable annuities is too complicated for this approach. While Koijen et al. (2011) use a simulationbased approach, we apply multi-stage stochastic programming (MSP). This approach is widely applied in financial engineering and operations research, and is especially handy when it comes to incorporate realistic constraints into the model, see, e.g., Carino and Ziemba (1998), Mulvey et al. (2008), Ferstl and Weissensteiner (2011) and Konicz et al. (2014a). By choosing the MSP approach, we are able to find the optimal dynamic strategy consisting of the aforementioned annuities, stocks and cash, thus, in contrast to Koijen et al. (2011), we allow for rebalancing the portfolio and expand the investment opportunities by adding liquid assets (stocks and cash). We further assume that annuities are irreversible (once purchased they can never be sold), therefore rebalancing decisions concern purchases of annuities, and purchases and sales of cash and stocks. MSP also allows to investigate the optimal strategy under exclusion of certain products. For example, we can explore whether any of the products providing nominal income are able to hedge against inflation.

In addition, our study contributes to the strand of literature developing scenario generation methods for multi-stage stochastic programs under inflation risk. The prices and the cash-flows from the annuities are stochastic and vary with the development of stock returns, an inflation index, and nominal and real yield curves. We model jointly these three sources of uncertainty with a vector autoregressive $\operatorname{VAR}(1)$ process, thus we can fully explore time-varying investment opportunities.

The remainder of the paper is organized as follows. Section 2 introduces available annuity products together with their cash-flows and prices. Section 3 describes the model for the uncertainty about the stock returns, the inflation index, and the real and nominal term structure, and explains the method for scenario generation. Section 4 presents the multi-stage stochastic programming formulation for both objective functions, while Sect. 5 illustrates the results from the optimization models. Section 6 concludes and suggests future work.

\section{Annuity products}

This study focuses on individuals upon retirement with an opportunity of investing in whole life annuities payable in arrears. By definition, the payout from these annuities starts at the end of a given interval, and is life contingent, i.e. pays as long as the retiree is alive, see Fig. 1 . We further distinguish between three types of annuities common in the market: nominal annuities with constant payments, inflation-linked annuities and variable annuities.

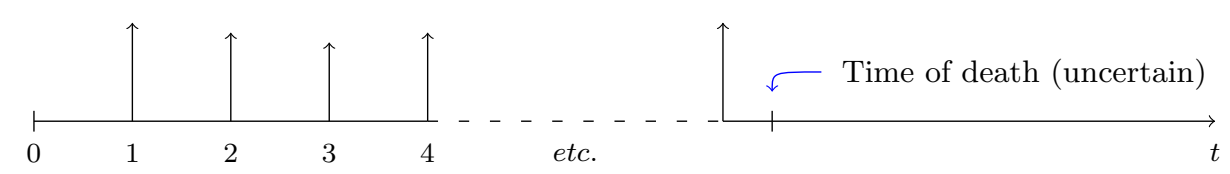

Figure 1: Cash-flows (indicated by arrows) from whole life annuities in arrears purchased upon time 0 . 
Nominal annuities provide fixed payments $c f_{t}^{N}$ determined at the time of the purchase,

$$
c f_{1}^{N}=1, \quad c f_{t}^{N}=c f_{t-1}^{N}=1,
$$

which are guaranteed as long as the person is alive. At any time $t$ after retirement, the price of this annuity is given by

$$
\text { price }_{x+t}^{N}=\sum_{s=t+1}^{\infty}{ }_{s-t} p_{x+t} \cdot e^{-y\left(\boldsymbol{\beta}_{t}^{N}, s\right)(s-t)}
$$

where, following the actuarial notation, ${ }_{s-t} p_{x+t}$ is a survival probability until time $s$ for an individual aged $x+t$, and $y\left(\boldsymbol{\beta}_{t}^{N}, s\right)$ is a nominal interest rate p.a. over the period $[t, s)$. We describe vector $\boldsymbol{\beta}_{t}^{N}$ later in Sect. 3 ,

Inflation-linked (real) annuities provide income linked to realized inflation rate, no matter how high the inflation rate is. Specifically, the payments increase with the rate of inflation reported as Retail Price Index (RPI),

$$
c f_{1}^{R}=I_{1}, \quad c f_{t}^{R}=c f_{t-1}^{R} \cdot e^{r p i(t-1, t)}=I_{t},
$$

where $r p i(t-1, t)$ is the inflation rate realized over the period $[t-1, t)$ and $I_{t}=\prod_{s=1}^{t} e^{r p i(s-1, s)}$. Consequently, neither the retiree nor the annuity provider knows the level of cash-flows at the purchase of the product. This value is revealed at the time of the payment, when the actual realized inflation is measured. To price real annuities, their providers use the real interest rates $y\left(\boldsymbol{\beta}_{t}^{R}, s\right)$, which are known at time $t$ for all maturities $s>t$,

$$
\operatorname{price}_{x+t}^{R}=\sum_{s=t+1}^{\infty} s-t p_{x+t} \cdot e^{-y\left(\boldsymbol{\beta}_{t}^{R}, s\right)(s-t)} \cdot I_{t} .
$$

Finally, variable annuities provide nominal income that is linked to risky assets such as bonds or equities. In this study, we assume that the underlying portfolio comprises the index MSCI UK. Similarly to real annuities, cash-flows from variable annuities are unknown upon the purchase of the product, and are first revealed when the actual stock returns are observed. The size of the payments depends on some assumed interest rate (AIR). Specifically, upon time $t$, the annuitant receives a cash-flow equal to the excess return from stock returns $r$ over the AIR $\bar{r}$,

$$
c f_{1}^{V}=e^{r(0,1)-\bar{r}}, \quad c f_{t}^{V}=c f_{t-1}^{V} \cdot e^{r(t-1, t)-\bar{r}}
$$

where $r(t-1, t)$ is the stock return realized over the period $[t-1, t)$. The common rates for AIR are between $3 \%$ and $7 \%$ p.a., see Dellinger (2006). The lower the AIR, the higher the expected excess return $r(t-1, t)-\bar{r}$ (implying that the annuity payments are likely to be increasing over time), and the higher the price, i.e.

$$
\operatorname{price}_{x+t}^{V}=\sum_{s=t+1}^{\infty}{ }_{s-t} p_{x+t} \cdot e^{-\bar{r}(s-t)} \cdot c f_{t}^{V}
$$




\section{Modeling uncertainty}

Term structure of nominal and real interest rates To model the uncertainty in our decision problem, we use nominal $(N)$ and real $(R)$ UK yield curves with a monthly frequency from October 1992 (when the inflation-targeting of the Bank of England began, see, e.g., Joyce et al. (2010)) to March 2014 11 To mitigate the problem of the curse of dimensionality inherent in our approach, we use the parametric Nelson and Siegel (1987) and Diebold and Li (2006) framework in order to condense the information in the two term structures of interest rates. More concise, both yield curves are modelled separately by a three-factor model as:

$$
y\left(\boldsymbol{\beta}_{t}^{i}, s\right)=\beta_{1, t}^{i}+\beta_{2, t}^{i}\left(\frac{1-e^{-\lambda_{t}^{i} s}}{\lambda_{t}^{i} s}\right)+\beta_{3, t}^{i}\left(\frac{1-e^{-\lambda_{t}^{i} s}}{\lambda_{t}^{i} s}-e^{-\lambda_{t}^{i} s}\right),
$$

with $i \in\{N, R\}$ and where $y\left(\boldsymbol{\beta}_{t}^{i}, s\right)$ indicates the (continuously compounded nominal/real) spot rate for maturity $s$ at stage $t$, given the parameter vector $\boldsymbol{\beta}_{t}^{i}=\left[\beta_{1, t}^{i}, \beta_{2, t}^{i}, \beta_{3, t}^{i}\right]^{\top}$ for level, slope and curvature of the term structure of interest rates.

We follow Diebold and Li (2006) and fix $\lambda^{i}$ to be time-independent and omit therefore the subscript $t$. The parameter $\lambda^{i}$ determines the maximum of the factor loading for the curvature. While a lower value ensures a better fit for long maturities, increasing this value enhances the fit for short maturities. We optimize $\lambda^{i}$ separately for nominal and real yields by minimizing the sum of squared differences between observed yields and fitted values from our model. Therefore we solve an iterative, nonlinear optimization problem, where in each iteration the $\boldsymbol{\beta}_{t}^{i}$ parameters are determined by OLS. Gilli et al. (2010) point out that this estimation through OLS might be prone to a collinearity problem for certain $\lambda^{i}$ values, which is particularly relevant if the ultimate goal is to model the evolution of yield curves over time. Therefore, to avoid such a problem we restrict $\lambda^{i}$ such that the correlation between the second and third factor loading is in the interval $[-0.7,0.7]$. The corresponding admissible range for $\lambda^{i}$ depends on the maturities for which we have observed yields. Nominal yields in our data set start at maturities of 1 year while real yields are only available for 2.5 years or more. For nominal yields, the restriction turns out to be non-binding, and the optimal $\lambda^{N}=0.42$. For real yields, however, the optimal $\lambda^{R}=0.34$ is at the upper end of its admissible range. In both cases the fit is very accurate, in most cases the coefficient of determination is above 0.99 .

Time-varying opportunities of term structure, inflation and stock returns The difference between nominal and real yields for different maturities is called the "break-even" inflation rate and can be interpreted as a result of expected inflation plus a premium for inflation risk minus a liquidity premium (given that nominal bonds are more liquid than the inflation-linked ones). A strand of literature tries to back out the components of the break-even inflation with different term structure models, see e.g. Joyce et al. (2010), Christensen et al. (2010) and Geyer et al. (2012). Given the focus of this paper, here we refrain from this attempt and include directly realized log inflation $r p i_{t}$ from the UK RPI 2

In line with Barberis (2000) and Campbell et al. (2003), we model time-varying realized stock returns, realized inflation, and nominal and real yield curves (represented by $\boldsymbol{\beta}_{t}^{N}$ and $\boldsymbol{\beta}_{t}^{R}$ ) with a VAR(1) model:

$$
\boldsymbol{\xi}_{t}=\mathbf{c}+\mathbf{A} \boldsymbol{\xi}_{t-1}+\mathbf{u}_{t},
$$

${ }^{1}$ http://www.bankofengland.co.uk/statistics/pages/yieldcurve/default.aspx

2 http://www.ons.gov.uk/ 
with $\boldsymbol{\xi}_{t}=\left[r_{t}, r p i_{t}, \boldsymbol{\beta}_{t}^{N}, \boldsymbol{\beta}_{t}^{R}\right]^{\prime}$, and where $\mathbf{c}$ is the $(8 \times 1)$ vector of intercepts, $\mathbf{A}$ is the $(8 \times 8)$ matrix of slope coefficients and $\mathbf{u}_{t}$ the $(8 \times 1)$ vector of i.i.d. innovations with $\mathbf{u} \sim N(0, \boldsymbol{\Sigma})$. The covariance of the innovations $\boldsymbol{\Sigma}$ is given by $\mathbb{E}\left(\mathbf{u} \mathbf{u}^{\top}\right)$. Thus, we allow the shocks to be cross-sectionally correlated, but assume that they are homoskedastic and independently distributed over time. The estimated parameters $\mathbf{c}$ and $\mathbf{A}$ are shown in Table 1.

\begin{tabular}{|c|c|c|c|c|c|c|c|c|}
\hline & $r_{t}$ & $r p i_{t}$ & $\beta_{1, t}^{N}$ & $\beta_{2, t}^{N}$ & $\beta_{3, t}^{N}$ & $\beta_{1, t}^{R}$ & $\beta_{2, t}^{R}$ & $\beta_{3, t}^{R}$ \\
\hline \multirow[t]{2}{*}{$c$} & 0.01 & 0.00 & 0.00 & -0.00 & -0.00 & 0.00 & -0.00 & -0.00 \\
\hline & {$[0.68]$} & {$[0.82]$} & {$[1.10]$} & {$[-0.36]$} & {$[-0.55]$} & {$[0.41]$} & {$[-2.08]$} & {$[-0.88]$} \\
\hline \multirow[t]{2}{*}{$r_{t-1}$} & 0.01 & 0.00 & 0.01 & 0.01 & -0.00 & 0.00 & -0.02 & -0.01 \\
\hline & {$[0.18]$} & {$[0.57]$} & {$[1.51]$} & {$[1.26]$} & {$[-0.25]$} & {$[0.56]$} & {$[-2.04]$} & {$[-0.94]$} \\
\hline \multirow[t]{2}{*}{$r p i_{t-1}$} & -0.59 & -0.01 & -0.06 & 0.11 & 0.35 & -0.02 & 0.40 & 0.07 \\
\hline & {$[-0.86]$} & {$[-0.13]$} & {$[-1.24]$} & [1.54] & {$[2.79]$} & {$[-0.50]$} & [3.97] & {$[0.46]$} \\
\hline \multirow{2}{*}{$\beta_{1, t-1}^{N}$} & -0.53 & 0.11 & 1.01 & -0.03 & -0.07 & -0.01 & 0.09 & 0.17 \\
\hline & {$[-1.01]$} & [2.30] & [28.34] & {$[-0.52]$} & {$[-0.75]$} & {$[-0.24]$} & [1.18] & {$[1.57]$} \\
\hline \multirow{2}{*}{$\beta_{2, t-1}^{N}$} & -0.13 & 0.10 & 0.01 & 1.01 & -0.09 & -0.02 & 0.14 & 0.06 \\
\hline & {$[-0.49]$} & [4.13] & {$[0.60]$} & [38.34] & {$[-1.88]$} & {$[-1.99]$} & [3.60] & [1.03] \\
\hline \multirow[t]{2}{*}{$\beta_{3, t-1}^{N}$} & -0.21 & 0.05 & 0.03 & 0.02 & 0.92 & 0.00 & 0.00 & 0.08 \\
\hline & {$[-1.28]$} & [3.09] & {$[2.27]$} & [1.33] & [30.23] & {$[0.00]$} & {$[0.12]$} & [2.19] \\
\hline \multirow{2}{*}{$\beta_{1, t-1}^{R}$} & 1.23 & -0.19 & -0.08 & 0.07 & 0.18 & 0.99 & -0.02 & -0.32 \\
\hline & {$[1.53]$} & [-2.55] & {$[-1.54]$} & {$[0.91]$} & {$[1.21]$} & [25.72] & {$[-0.21]$} & {$[-1.86]$} \\
\hline \multirow{2}{*}{$\beta_{2, t-1}^{R}$} & 0.02 & -0.13 & -0.02 & -0.06 & 0.11 & 0.03 & 0.87 & -0.10 \\
\hline & {$[0.08]$} & {$[-5.03]$} & {$[-1.03]$} & {$[-2.09]$} & {$[2.17]$} & {$[2.07]$} & [21.29] & {$[-1.64]$} \\
\hline \multirow[t]{2}{*}{$\beta_{3, t-1}^{R}$} & 0.14 & -0.04 & -0.01 & -0.01 & -0.03 & 0.01 & -0.02 & 0.86 \\
\hline & {$[0.74]$} & {$[-2.17]$} & {$[-0.91]$} & {$[-0.28]$} & {$[-0.91]$} & {$[0.88]$} & {$[-0.73]$} & {$[21.19]$} \\
\hline$R^{2}$ & 0.03 & 0.11 & 0.97 & 0.97 & 0.94 & 0.97 & 0.94 & 0.87 \\
\hline
\end{tabular}

Table 1: VAR(1) parameters and $t$-statistics (in squared brackets) for stock returns, inflation rate, and nominal and real yield curves, estimated from monthly data from October 1992 to March 2014.

Given that all eigenvalues of $\mathbf{A}$ have modulus less than one, the stochastic process in equation (8) is stable with unconditional expected mean $\boldsymbol{\mu}$ and covariance $\boldsymbol{\Gamma}$ for the steady state at $t=\infty$, see, e.g., Lütkepohl 2005):

$$
\begin{aligned}
\boldsymbol{\mu} & :=(\mathbf{I}-\mathbf{A})^{-1} \mathbf{c} \\
\operatorname{vec}(\boldsymbol{\Gamma}) & :=(\mathbf{I}-\mathbf{A} \otimes \mathbf{A})^{-1} \operatorname{vec}(\boldsymbol{\Sigma}),
\end{aligned}
$$

where I refers to the identity matrix, the symbol $\otimes$ is the Kronecker product and "vec" transforms a $(K \times K)$ matrix into a $\left(K^{2} \times 1\right)$ vector by stacking the columns. In the steady state, both yield curves are increasing (15y nominal yields at $3.5 \%$ p.a.), and the average break-even inflation rate is equal to $2.95 \%$ p.a.. Stocks have a drift of $7.00 \%$ p.a. and a volatility of $15.22 \%$. The correlation between the inflation rates and stock returns is nearly zero (0.0375).

Scenario generation In a multi-stage stochastic programming, the uncertainty is represented by a scenario tree. As shown on Fig. 2, a scenario tree consists of nodes $n \in \mathcal{N}_{t}$ uniquely assigned to periods $t$, and representing possible outcomes for the uncertainties, $\boldsymbol{\xi}_{t, n}=\left[r_{t, n}, r p i_{t, n}, \beta_{t, n}^{N}, \beta_{t, n}^{R}\right]^{\prime}$. At the initial stage $t_{0}$ there is only one node $n_{0}$, which is the ancestor for all the nodes $n^{+}$at the subsequent stage $t_{1}$. These nodes are further the ancestors for their children nodes $n^{++}$, etc., until the final stage $T$. As the nodes at the final stage have no children, they are called the leaves. We define a scenario $\mathcal{S}^{n}$ as a single branch from the root node to the leaf, i.e. each scenario consists of a leaf node $n$ and all its predecessors $n^{-}, n^{--}, \ldots, n_{0}$. Consequently, the number of scenarios in the tree equals the number of leaves. Each node has a probability $p r_{n}$, so that $\forall_{t} \sum_{n \in \mathcal{N}_{t}} p r_{n}=1$, implying the probability of each scenario $\mathcal{S}^{n}$ is 
equal to the product of the probabilities of all the nodes in the scenario.

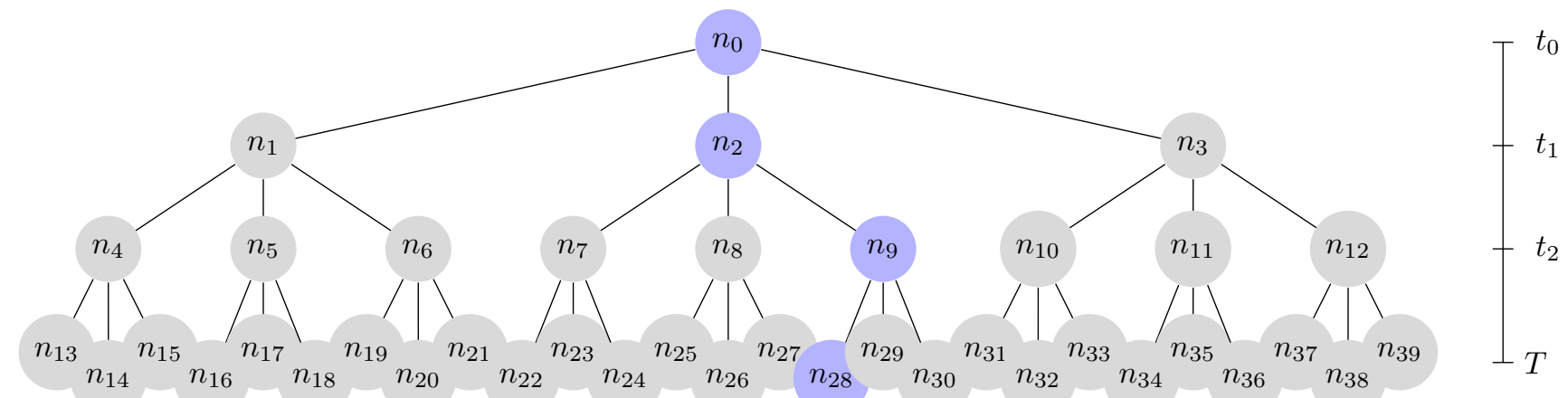

Figure 2: An example of a scenario tree with three periods, a branching factor of 3 , and $3^{3}=27$ scenarios defined as a single path from the root node to the leaf (such as the one marked in blue).

When working with an MSP approach, one must be aware of the curse of dimensionality. Specifically, the size of the tree grows exponentially with the number of periods, implying that for a large number of periods the problem becomes computationally intractable. Therefore, when generating scenarios, we approximate the discrete-time multivariate process in Eq. (8) with a few mass points, accordingly reducing the computational complexity.

To uncouple our results from a particular root note, we start the tree construction from the unconditional expected values as done, e.g., by Campbell et al. (2003) and Ferstl and Weissensteiner (2011). We use the technique proposed by Høyland and Wallace (2001) and Høyland et al. (2003) to match the first four moments and the correlations with a branching factor of 14 . Given that we use decision steps longer than one year but calibrate the VAR process to monthly data, we follow Pedersen et al. (2013) to calculate aggregated stock returns and inflation between two decision stages.

For notation brevity, we define $\boldsymbol{\zeta}_{\tau}$ as the vector of cumulated stock returns, cumulated inflation, and the Nelson/Siegel parameters $3^{3}$ and introduce an indicator matrix $\mathbf{J}=\operatorname{diag}(1,1,0,0,0,0,0,0)$. The following equations show how to calculate the expectation and the covariance of $\boldsymbol{\zeta}_{\tau}$ for two time steps (i.e., months) of Eq. (8), and for a general number of time steps:

$$
\begin{aligned}
& \boldsymbol{\zeta}_{1}=\boldsymbol{\xi}_{1}, \\
& \boldsymbol{\zeta}_{2}=\underbrace{(\mathbf{I}+\mathbf{A}) \mathbf{c}+\mathbf{A}^{2} \boldsymbol{\xi}_{0}+\mathbf{A} \mathbf{u}_{1}+\mathbf{u}_{2}}_{\boldsymbol{\xi}_{2}}+\mathbf{J}(\underbrace{\mathbf{c}+\mathbf{A} \boldsymbol{\xi}_{0}+\mathbf{u}_{1}}_{\boldsymbol{\xi}_{1}}) .
\end{aligned}
$$

The expected value of $\boldsymbol{\zeta}_{2}$ results as:

$$
\mathbb{E}\left(\boldsymbol{\zeta}_{2}\right)=(\mathbf{I}+\mathbf{A}+\mathbf{J}) \mathbf{c}+\left(\mathbf{J} \mathbf{A}+\mathbf{A}^{2}\right) \boldsymbol{\xi}_{0}
$$

and the corresponding covariance as:

$$
\mathbb{V}\left(\boldsymbol{\zeta}_{2}\right)=\boldsymbol{\Sigma}+(\mathbf{J}+\mathbf{A}) \boldsymbol{\Sigma}(\mathbf{J}+\mathbf{A})^{\top}
$$

Expanding Eq. (9) to more discrete steps $(T)$ and collecting the terms, we obtain the following general

\footnotetext{
${ }^{3}$ The difference to $\boldsymbol{\xi}$ is given by first row, see Eq. 8). While in $\boldsymbol{\xi}$ realized inflation and stock returns are on a monthly basis, $\boldsymbol{\zeta}_{\tau}$ cumulates $\tau$ monthly rates. The Nelson/Siegel parameter vector is the same for $\boldsymbol{\xi}$ and $\boldsymbol{\zeta}$.
} 
result:

$$
\mathbb{E}\left(\boldsymbol{\zeta}_{T}\right)=\left(\left(\sum_{i=1}^{T-1}(\mathbf{I}+\mathbf{J}(T-i)) \mathbf{A}^{i-1}\right)+\mathbf{A}^{T-1}\right) \mathbf{c}+\left(\mathbf{A}^{T}+\sum_{i=1}^{T-1} \mathbf{J} \mathbf{A}^{i}\right) \boldsymbol{\xi}_{0}
$$

and

$$
\begin{aligned}
\mathbb{V}\left(\boldsymbol{\zeta}_{T}\right) & =\boldsymbol{\Sigma} \\
& +(\mathbf{J}+\mathbf{A}) \boldsymbol{\Sigma}(\mathbf{J}+\mathbf{A})^{\top} \\
& +\left(\mathbf{J}+\mathbf{J} \mathbf{A}+\mathbf{A}^{2}\right) \boldsymbol{\Sigma}\left(\mathbf{J}+\mathbf{J} \mathbf{A}+\mathbf{A}^{2}\right)^{\top} \\
& +\ldots \\
& +\left(\mathbf{A}^{T-1}+\sum_{i=1}^{T-1} \mathbf{J} \mathbf{A}^{i-1}\right) \boldsymbol{\Sigma}\left(\mathbf{A}^{T-1}+\sum_{i=1}^{T-1} \mathbf{J} \mathbf{A}^{i-1}\right)^{\top} .
\end{aligned}
$$

Thus, we use 10 and 11 to build our scenario tree.

\section{Optimization}

Multi-stage stochastic programming is an optimization approach, where the decisions are computed numerically at each node of the tree, given the anticipation of the possible future outcomes, see, e.g., Birge and Louveaux (1997). After the outcomes have been observed, the decisions for the next period are made. These depend not only on the realizations of the random vector but also on the previously made decisions. Because the multi-stage stochastic programming approach combines anticipative and adaptive models in one mathematical framework, it is particularly appealing in financial applications. For example, an investor composes his portfolio based on anticipation of possible future movements of asset prices, and rebalances the portfolio as prices change, see Zenios (2008).

In this study we explore two optimization models, which differ mostly with respect to the objective function. Throughout this section, we use capital letters to denote the variables and lower-case letters to specify the parameters.

Power utility maximization In the first model we consider an investor who obtains utility from real consumption. Similarly to Brown et al. (2001) and Koijen et al. (2011), we maximize the expected real consumption over the stochastic lifetime (i.e. the time of death is unknown),

$$
\max \mathbb{E}_{t_{0}, w_{0}}\left[\sum_{t=t_{0}}^{\infty}{ }_{t} p_{x} u\left(t, C_{t}\right)\right]
$$

Function $u$ denotes a utility function with a constant relative risk aversion (CRRA) $1-\gamma$, and a time preference factor $\rho$, reflecting how important the current consumption is relatively to the consumption in the future,

$$
u\left(t, C_{t}\right)=\frac{1}{\gamma} e^{-\rho t}\left(\frac{C_{t}}{I_{t}}\right)^{\gamma}
$$

where $I_{t}$ is the level of the inflation index (RPI) at time $t$ (we normalize it by assuming that the current inflation index $I_{t_{0}}$ is equal to 1 ), and $\mathbb{E}$ denotes the expectation operator under the physical probability measure $\mathbb{P}$, given that at time $t_{0}$ the individual has an initial wealth $w_{0}$. We multiply the utility at 
each period by the probability that a retiree aged $x$ survives until time $t,{ }_{t} p_{x}$, which we calculate from mortality tables 4

As the curse of dimensionality characteristic for multi-stage stochastic programming does not allow us to make optimal decisions for the entire lifetime of the individual, we must simplify the model. Specifically, we choose some horizon $T$ and define the scenario tree only up to this horizon. To make sure that the individual has enough savings for the rest of his life, we further maximize the utility of the final wealth upon horizon $T$. Consequently, we calculate the optimal consumption and asset allocation only up to time $T-1$, which can be interpreted as the annuitization time (i.e. the retiree has to convert all his wealth in cash and stocks into annuities). From $T$ and onwards the individual no longer rebalances the portfolio, but consumes the cash-flows from the annuities that he has purchased during the period $\left[t_{0}, T-1\right]$, as shown on Fig. 3.

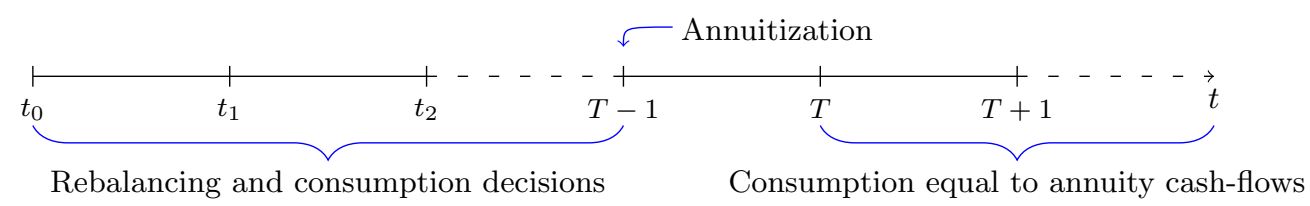

Figure 3: Overview of the model.

Accordingly, we define the nodal representation of the objective function defined in Eq. 12 as

$$
\max \sum_{t=t_{0}}^{T-1}{ }_{t} p_{x} \sum_{n \in \mathcal{N}_{t}} f_{t, n}^{1-\gamma} u\left(t, C_{t, n}\right) \cdot p r_{n}+{ }_{T} p_{x} \sum_{n \in \mathcal{N}_{T}} f_{T, n}^{1-\gamma} u\left(T, W_{T, n}\right) \cdot p r_{n}
$$

where

$$
u\left(t, C_{t, n}\right)=\frac{1}{\gamma} e^{-\rho t}\left(\frac{C_{t, n}}{I_{t, n}}\right)^{\gamma}, \quad u\left(t, W_{t, n}\right)=\frac{1}{\gamma} e^{-\rho t}\left(\frac{W_{t, n}}{I_{t, n}}\right)^{\gamma},
$$

$C_{t, n}$ is the consumption during the subsequent period, $W_{T, n}$ is the value of wealth upon horizon, $p r_{n}$ is the probability of being at node $n$, and $f_{t, n}$ is the multiplier accounting for the length of the subsequent interval. We calculate $f_{t, n}$ as

$$
f_{t, n}= \begin{cases}\sum_{s=t}^{t+\Delta t}{ }_{s-t} p_{x+t} e^{-y\left(\beta_{t, n}^{R}, s\right)(s-t)}, & t=t_{0}, \ldots, T-1, n \in \mathcal{N}_{t}, \\ \sum_{s=t}^{\omega-x-t}{ }_{s-t} p_{x+t} e^{-y\left(\beta_{t, n}^{R}, s\right)(s-t)}, & t=T, n \in \mathcal{N}_{T},\end{cases}
$$

where $\omega$ is the maximum age, at which the individual is assumed to be dead with certainty. The multiplier $f_{t, n}$ is necessary because we are interested in the utility of the yearly consumption $u\left(t, C_{t, n} / f_{t, n}\right)$ taken each year during $\Delta t$, i.e. $f_{t, n} \cdot u\left(t, C_{t, n} / f_{t, n}\right)=f_{t, n}^{1-\gamma} \cdot u\left(t, C_{t, n}\right)$. By definition of the utility function we further have that $C_{t, n}>0$ and $W_{T, n}>0$ for $\gamma \in(-\infty, 1) \backslash\{0\}$.

Let $\mathcal{A}$ denote a set of available assets: nominal, real, and variable annuities, cash, and stocks, whereas $\mathcal{K} \subset \mathcal{A}$ is the subset including cash and stocks. For each asset $a \in \mathcal{A}$, we define variable Buy $y_{t, n}^{a}$ denoting the number of units of asset $a$ purchased, and variable $H_{o l d}^{a}, n$ denoting the number of units of asset $a$ held at time $t$ and node $n$. Because annuities are often irreversible (i.e. once purchased they can never be sold) or have prohibitive transaction costs, we do not allow for selling these products. Nevertheless, we

\footnotetext{
${ }^{4} \mathrm{We}$ use British mortality tables for males based on 2000-2006 experience from UK selfadministered pension schemes. Source: http://www.actuaries.org.uk/research-and-resources/documents/ s1pml-all-pensioners-excluding-dependants-male-lives
} 
define the variable $\mathrm{Sell}_{t, n}^{a}$ for cash and stocks. Then the optimization problem consists of the following constraints: the budget constraint, the inventory constraint, the annuitization constraint, and the nonnegativity constraint.

In the budget constraint we equal the incoming payments (the initial wealth, the cash-flows from the annuities, and the cash-flows from sales) to the outgoing payments (consumption and the purchase of new assets),

$$
\begin{aligned}
C_{t, n}= & w_{0} \mathbf{1}_{\left\{t=t_{0}\right\}}+\sum_{a \in \mathcal{A}} c f_{t, n}^{a} \operatorname{Hold}_{t-1, n^{-}}^{a}+\sum_{a \in \mathcal{K}} \operatorname{price}_{t, n}^{a} \operatorname{Sell}_{t, n}^{a} \mathbf{1}_{\{t<T\}}-\sum_{a \in \mathcal{A}} \operatorname{price}_{t, n}^{a} \text { Buy }_{t, n}^{a} \mathbf{1}_{\{t<T\}}, \\
& t=t_{0}, \ldots, T, n \in \mathcal{N}_{t},
\end{aligned}
$$

and calculate the value of savings upon horizon, equal to the sum of the cash-flows provided by the annuities held in the portfolio, and of the market value of these annuities 5

$$
W_{t, n}=\sum_{a \in \mathcal{A}}\left(c f_{t, n}^{a}+\text { price }_{t, n}^{a}\right) H o l d_{t-1, n^{-}}^{a}, \quad t=T, n \in \mathcal{N}_{T}
$$

The nominal and real interest rates, and thus annuity prices and income are the parameters in the model calculated based on the scenario tree,

$$
\begin{aligned}
c f_{t, n}^{N} & =c f_{t-1, n^{-}}^{N}, \quad t=t_{0}, \ldots, T, n \in \mathcal{N}_{t}, \\
c f_{t, n}^{R} & =c f_{t-1, n^{-}}^{R} \cdot e^{r p i_{n}(t-1, t)}, \quad t=t_{0}, \ldots, T, n \in \mathcal{N}_{t}, \\
c f_{t, n}^{V} & =c f_{t-1, n^{-}}^{V} \cdot e^{r_{n}(t-1, t)-\bar{r}}, \quad t=t_{0}, \ldots, T, n \in \mathcal{N}_{t},
\end{aligned}
$$

and

$$
\begin{aligned}
\text { price }_{t, n}^{N} & =\sum_{s=t+1}^{\omega-x-t} s-t p_{x+t} \cdot e^{-y\left(\beta_{t, n}^{N}, s\right)(s-t)}, \quad t=t_{0}, \ldots, T, n \in \mathcal{N}_{t}, \\
\text { price }_{t, n}^{R} & =\sum_{s=t+1}^{\omega-x-t} s-t p_{x+t} \cdot e^{-y\left(\beta_{t, n}^{R}, s\right)(s-t)} \cdot I_{t, n}, \quad t=t_{0}, \ldots, T, n \in \mathcal{N}_{t}, \\
\text { price }_{t, n}^{V} & =\sum_{s=t+1}^{\omega-x-t} s-t p_{x+t} \cdot e^{-\bar{r}(s-t)} \cdot c f_{t, n}^{V}, \quad t=t_{0}, \ldots, T, n \in \mathcal{N}_{t} .
\end{aligned}
$$

The inventory constraint keeps track of the current holdings in a given asset,

$$
\operatorname{Hold}_{t, n}^{a}=\operatorname{Hold}_{t-1, n^{-}}^{a} \mathbf{1}_{\left\{t>t_{0}\right\}}+\operatorname{Buy}_{t, n}^{a}-\operatorname{Sell}_{t, n}^{a} \mathbf{1}_{\{a \in \mathcal{K}\}}, \quad t=t_{1}, \ldots, T-1, n \in \mathcal{N}_{t}, a \in \mathcal{A} .(25)
$$

We further add a terminal condition reflecting annuitization, i.e. the retiree converts all the savings held on the bank account and in stocks into annuities the latest upon time $T-1$, so that upon horizon his wealth consists only of annuities,

$$
\operatorname{Hold}_{t, n}^{a}=0, \quad t=T-1, n \in \mathcal{N}_{t}, a \in \mathcal{K} .
$$

\footnotetext{
${ }^{5}$ By definition of annuities in arrears, the current price does not include the current cash-flows from the annuities.
} 
Finally, we add the non-negativity constraints on the purchase, hold and sale variables,

$$
\begin{array}{r}
\text { Buy }_{t, n}^{a} \geq 0, \text { Hold }_{t, n}^{a} \geq 0, \quad t=t_{0}, \ldots, T-1, n \in \mathcal{N}_{t}, a \in \mathcal{A}, \\
\text { Sell }_{t, n}^{a} \geq 0, \quad t=t_{0}, \ldots, T-1, n \in \mathcal{N}_{t}, a \in \mathcal{K},
\end{array}
$$

implying that we do not allow for having a short position in any asset, or for borrowing money.

Loss disutility minimization The second objective is to minimize a disutility function, written in terms of a loss function. This objective penalizes squared deviations from a certain target $\widehat{C}$, which defines the level of consumption necessary to cover standard living costs. While some retirees may consider penalizing the deviations above the target as a drawback, doing so prevents the retiree from exposure for unnecessary financial risk. Once the target is achieved, the individual follows a more riskaverse strategy. At each period the target $\widehat{C}$ is multiplied by the RPI index, thus accounting for an increase in living costs. The objective is as follows:

$$
\min \mathbb{E}_{t_{0}, w_{0}}\left[\sum_{t=t_{0}}^{\infty}{ }_{t} p_{x} \mathcal{L}\left(t, C_{t}\right)\right], \quad \mathcal{L}\left(t, C_{t}\right)=e^{-v t}\left(\widehat{C} \cdot I_{t}-C_{t}\right)^{2},
$$

where $v$ is the subjective discount factor reflecting how important minimizing current deviations from the target is relatively to minimizing deviations in the future, and ${ }_{t} p_{x}$ is the survival probability until time $t$ of the retiree aged $x$. A similar loss function has been considered in, e.g., Gerrard et al. (2004) and Di Giacinto et al. (2014), who applied a dynamic programming approach to find the optimal solution in a closed form. However, none of these studies optimize over the target, nor do they include inflation risk and inflation-linked products.

To implement this objective in a multi-stage stochastic programming framework, we rewrite Eq. 29, to a nodal representation:

$$
\min \sum_{t=t_{0}}^{T}{ }_{t} p_{x} \sum_{n \in \mathcal{N}_{t}} \mathcal{L}\left(t, C_{t, n}\right) \cdot p r_{n}, \quad \mathcal{L}\left(t, C_{t, n}\right)=e^{-v t}\left(\widehat{C} \cdot I_{t, n}-C_{t, n}\right)^{2} .
$$

To ensure computational tractability, we sum the disutility function up to a finite horizon $T$. Thus, similarly to the CRRA utility maximization, the retiree makes consumption and investment decisions only up to time $T-1$, whereas from $T$ and onwards he consumes the income from the annuities that he has purchased during the period $\left[t_{0}, T-1\right]$.

The model constraints are identical to the case of the power utility maximization. Specifically, the model comprises the budget constraint (17), the inventory constraint [25], the annuitization constraint (26), the non-negativity constraints $(27,28)$, and a constraint defining the risk aversion of the retiree

$$
\widehat{C} \geq c^{\min },
$$

where $c^{\text {min }}$ is a lower limit for the target defined by the individual. The higher the target, the less risk averse the retiree is. 


\section{Numerical results}

The scope of this paper is to investigate whether inflation-linked annuities are a good investment, and if so, under which circumstances. Afterwards, we search for an optimal investment strategy in the absence of inflation-linked products, and analyze the corresponding level of consumption.

We choose the intervals of length $\Delta t=5$ years between the decision stages, and the horizon $T=20$ years. Accordingly, the investor makes consumption and investment decisions, starting at his retirement (assumed age 65), and until he reaches age 85. Upon that age and until his death, his consumption is equal to the cash-flows received from the whole life annuities purchased during the first 20 years of retirement.

Among the available assets we consider a bank account with a floating spot rate $y\left(\boldsymbol{\beta}_{t}^{N}, 5\right)$, the MSCI UK stock index, and three types of whole life annuities in arrears: nominal, inflation-linked (real) and variable annuities with $\bar{r}=5 \%$. We assume that all the annuities are fairly priced (equations $(19)-(24)$ ), and provide cash-flows every fifth year, starting in the period following the purchase and ending upon the individual's death. The cash-flows from nominal annuities are constant (in nominal terms), whereas the cash-flows from real and variable annuities vary with inflation and stock returns. In addition, the prices of all annuities vary across scenarios due to changes in stock returns, the inflation index, and nominal and real yield curves. Table 2 shows the expected prices and cash-flows in nominal terms of each annuity, and their development over time for the first 20 years after retirement. Upon retirement the cheapest product is the variable annuity, whereas the most expensive product is the real annuity.

\begin{tabular}{l|ccccc|ccccc} 
& \multicolumn{4}{|c}{ Prices (in £), $\mathbb{E}\left[\right.$ price $\left._{t}^{a}\right]$} & \multicolumn{4}{c}{ Cash-flows (in $£), \mathbb{E}\left[c f_{t}^{a}\right]$} \\
Annuity & 65 & 70 & 75 & 80 & 85 & 65 & 70 & 75 & 80 & 85 \\
\hline Nominal annuities & 2.02 & 1.63 & 1.22 & 0.85 & 0.54 & 0.00 & 1.00 & 1.00 & 1.00 & 1.00 \\
Real annuities & 2.86 & 2.64 & 2.30 & 1.87 & 1.40 & 0.00 & 1.22 & 1.48 & 1.80 & 2.20 \\
Variable annuities & 1.65 & 1.54 & 1.37 & 1.13 & 0.85 & 0.00 & 1.17 & 1.37 & 1.62 & 1.91
\end{tabular}

Table 2: Expected prices and cash-flows in nominal terms from whole life annuities in arrears paying $c f_{t, n}^{a}$ every fifth year.

Break-even age Towler (2013) argues that 95\% of British retirees do not bother to protect their savings against inflation by purchasing real annuities, and that a possible explanation for such behaviour is that retirees find inflation-linked products too expensive. Before deciding which annuity to buy, individuals often compare the payout from different products. The cash-flows from real annuities are always lower for some years after the purchase than the cash-flows from nominal annuities with constant payments, and it may take many years to see the benefits of real annuities. To exemplify, given our choice of parameters, for a lump sum of $£ 100$ the retiree can purchase 49.5 units of nominal annuities or 35 units of real annuities. The income upon age 70 from real annuities is $£ 42.5(35 \cdot 1.22)$, which is $15 \%$ lower than from nominal annuities with constant payments. Given a realized inflation equal to $\mathbb{E}\left[r p i_{t}\right]=3.92 \%$, it will take 14 years before the smaller payouts from inflation-linked annuity exceed the fixed rate payouts. Fig. 4 shows the accumulated payouts from both annuities. We observe that the break-even age (i.e. the time when the payouts cross) is around 79 years. If the realized inflation rate is lower than expected, the individual has to wait even longer for his payments to exceed those from the nominal annuity ${ }^{6}$

${ }^{6}$ The inflation target range of the Bank of England is between 1 and 3\%, see http://www.bankofengland.co.uk/ monetarypolicy/Pages/framework/framework. aspx 


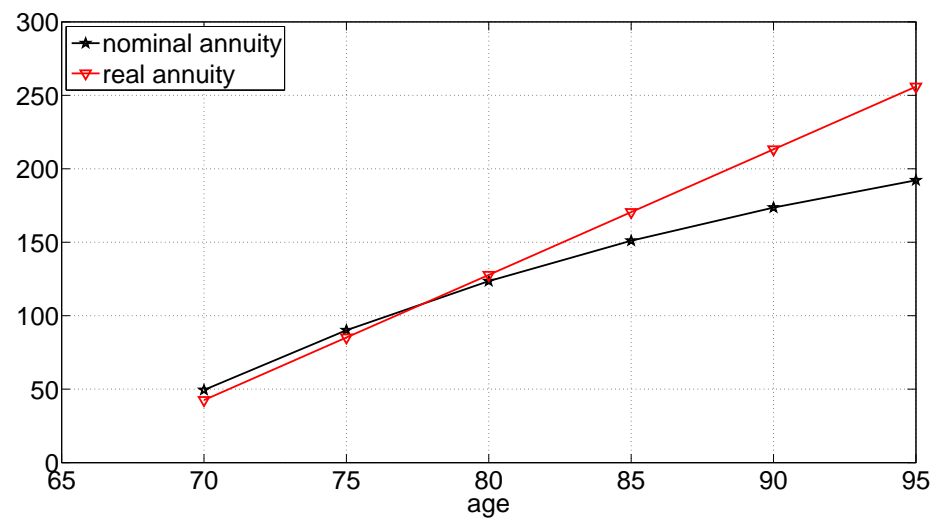

Figure 4: The accumulated payout in real terms from a nominal annuity with constant payments and from an inflation-linked annuity, both purchased upon retirement and paid in arrears every fifth year, given $£ 100$ invested upon retirement.

Optimization-based results Looking at the break-even age, not surprisingly the individuals feel reluctant to purchase a real annuity. Therefore, to investigate whether these products are beneficial for individuals, we consider an optimization-based approach.

As described in the previous section, we study two different objective functions implying different consumption and investment decisions. We implement the multi-stage stochastic models in GAMS 24.1.3. We use MOSEK 7.0.0.75 to solve the power utility maximization problem, and CPLEX 12.5.1.0 to solve the loss minimization problem. The scenario tree has four stages, each with a branching factor of 14 (which is the minimum number of branches providing enough uncertainty without arbitrage opportunities). Consequently, the number of scenarios in the tree is equal to $14^{4}=38,416$. The running time on a Dell computer with an Intel Core i5-2520M $2.50 \mathrm{GHz}$ processor and 4 GB RAM is approximately 1.5 minutes.

To get an economic intuition for the optimal decisions (which are non-linear in the state variables), we follow Koijen et al. (2011), and approximate the strategy using linear decision rules. We run multilinear regressions to examine the optimal conditional and unconditional asset allocation, however, in contrast to the mentioned study, we investigate how the optimal decisions are affected by conditional future state variables relatively to the current state. Among the expected state variables of the successor nodes, we consider stock returns and changes in the level of inflation, long-term real, and long-term nominal interest rates:

$$
\begin{aligned}
Y_{t, n}^{1} & =\mathbb{E}\left[r_{t+1}\right], \quad \mathbb{E}\left[r_{t+1}\right]=\sum_{n^{+} \in \mathcal{N}_{t+1}} r_{t+1, n^{+}} \cdot p r_{n^{+}}, \\
Y_{t, n}^{2} & =\mathbb{E}\left[r p i_{t+1}\right]-r p i_{t, n}, \quad \mathbb{E}\left[r p i_{t+1}\right]=\sum_{n^{+} \in \mathcal{N}_{t+1}} r p i_{t+1, n^{+}} \cdot p r_{n^{+}}, \\
Y_{t, n}^{3} & =\mathbb{E}\left[y\left(\boldsymbol{\beta}_{t+1}^{R}, 30\right)\right]-y\left(\boldsymbol{\beta}_{t, n}^{R}, 30\right), \quad \mathbb{E}\left[y\left(\boldsymbol{\beta}_{t+1}^{R}, 30\right)\right]=\sum_{n^{+} \in \mathcal{N}_{t+1}} y\left(\boldsymbol{\beta}_{t+1, n^{+}}^{R}, 30\right) \cdot p r_{n^{+}}, \\
Y_{t, n}^{4} & =\mathbb{E}\left[y\left(\boldsymbol{\beta}_{t+1}^{N}, 30\right)\right]-y\left(\boldsymbol{\beta}_{t, n}^{N}, 30\right), \quad \mathbb{E}\left[y\left(\boldsymbol{\beta}_{t+1}^{N}, 30\right)\right]=\sum_{n^{+} \in \mathcal{N}_{t+1}} y\left(\boldsymbol{\beta}_{t+1, n^{+}}^{N}, 30\right) \cdot p r_{n^{+}} .
\end{aligned}
$$

We further normalize the state variables

$$
\tilde{Y}_{t, n}^{j}=\frac{Y_{t, n}^{j}-\mathbb{E}\left(Y_{t}^{j}\right)}{\sigma\left(Y_{t}^{j}\right)}, \quad j=1, \ldots, 4,
$$


where $Y_{t}^{j}$ is a vector of the $j$-th state variable at all nodes assigned to stage $t$, so that we can approximate the optimal decisions consumption by

$$
\begin{aligned}
& \frac{C_{t, n}}{c f_{t, n}^{a} \text { Hold }_{t-1, n^{-}}^{a}+\operatorname{price}_{t, n}^{a} \text { Sell lan }_{t, n}^{a}} \approx \alpha_{t}^{C, 0}+\sum_{j=1}^{4} \alpha_{t}^{C, j} \widetilde{Y}_{t, n}^{j}, \quad t=t_{0}, \ldots, T-1, n \in \mathcal{N}_{t}, \\
& \frac{\operatorname{price}_{t, n}^{a}\left(B u y_{t, n}^{a}-S e l l_{t, n}^{a}\right)}{I_{t, n}} \approx \alpha_{t}^{a, 0}+\sum_{j=1}^{4} \alpha_{t}^{a, j} \widetilde{Y}_{t, n}^{j}, \quad t=t_{0}, \ldots, T-1, n \in \mathcal{N}_{t}, a \in \mathcal{A} .
\end{aligned}
$$

The first equation defines the consumption relative to the retirement income, which consists of the cashflows from the purchased annuities and the cash-flows from selling cash and stocks. The second equation defines the total traded amount at time $t$ equal to the difference between the purchase and sale amount of a given asset in real terms (recall that $\operatorname{Sell}_{t, n}^{a}=0$ for all the annuities). Accordingly, the terms $\alpha_{t}^{C, 0}$ and $\alpha_{t}^{a, 0}$ are the unconditional relative consumption and traded amount, and the slope coefficients $\alpha_{t}^{C, j}$ and $\alpha_{t}^{a, j}$ are the change in the corresponding variables for a one standard deviation increase in the corresponding $j$-th state variable.

Power utility maximization Figure 5 a shows the expected optimal consumption and retirement income for an individual with risk aversion $\gamma=-7$ and $\gamma=-2$. Consistently with Yaari (1965), in the absence of a bequest motive the individual holds his assets in life contingent annuities rather than in cash and stocks, and consistently with Milevsky and Young (2007), he does not delay his annuitization decision, but purchases annuities as soon as he seizes a chance to do so. In particular, he allocates his wealth mainly to two types of annuities: real and variable. As also shown in Table 3 , the ratio between the assets varies with the risk aversion. The more risk averse retiree $(\gamma=-7)$ allocates $68 \%$ of the portfolio to real annuities and $30 \%$ to variable annuities, whereas the less risk averse retiree $(\gamma=-2)$ allocates, respectively, 29\% and 71\%. Thus, in line with Campbell and Viceira (2001), Koijen et al. (2011), and Han and Hung (2012) - the more risk averse the investor, the more he is concerned about the uncertainty of his real income. In addition, as also shown in Koijen et al. (2011), the allocation to nominal annuities is marginal for all levels of $\gamma$.

The more risk averse individual expects a 5-year consumption level upon retirement of £29.7, and this amount decreases over time to $£ 24$ upon survival until age 110 (see Fig. 5a. The less risk averse retiree consumes initially £33.0, then he increases his consumption until horizon $T$, and decreases afterwards to obtain $£ 23.5$ upon age 110 . Looking at the volatility of consumption, we conclude that it varies significantly with each scenario. Consumption is approximately twice as volatile for the retiree with $\gamma=-2$ than for $\gamma=-7$, and its standard deviation at age 85 is as high as £21.4.

We further observe that during retirement the individual consumes almost the entire cash-flow from the annuities (the black line indicating consumption on Fig. $5 \mathrm{a}$ is nearly as high as the bars showing the annuity payouts and cash-flows from the sales). Table 4 illustrates these findings in detail. Upon retirement, the less risk averse individual consumes $\alpha_{t_{0}}^{C, 0}=33 \%$ of his savings (£33), and spends the rest on the purchase of real (£19.4) and variable (£47.6) annuities. At the later stages, the unconditional consumption is as high as $\alpha_{t}^{C, 0}=98 \%$ of the retirement income, and increases to $100 \%$ per one standard deviation when the retiree expects high stock returns in the next period $\left(\alpha_{t}^{C, 1}=2 \%\right)$, and to $99 \%$ per one standard deviation when he expects an increase in real interest rates $\left(\alpha_{t}^{C, 4}=1 \%\right)$. Whenever he anticipates a decrease in stocks and real interest rates, he consumes less and spends the residual cash-flow primarily on the purchase of real annuities.

Nevertheless, during retirement the unconditional purchase amount of any of the assets is marginal 

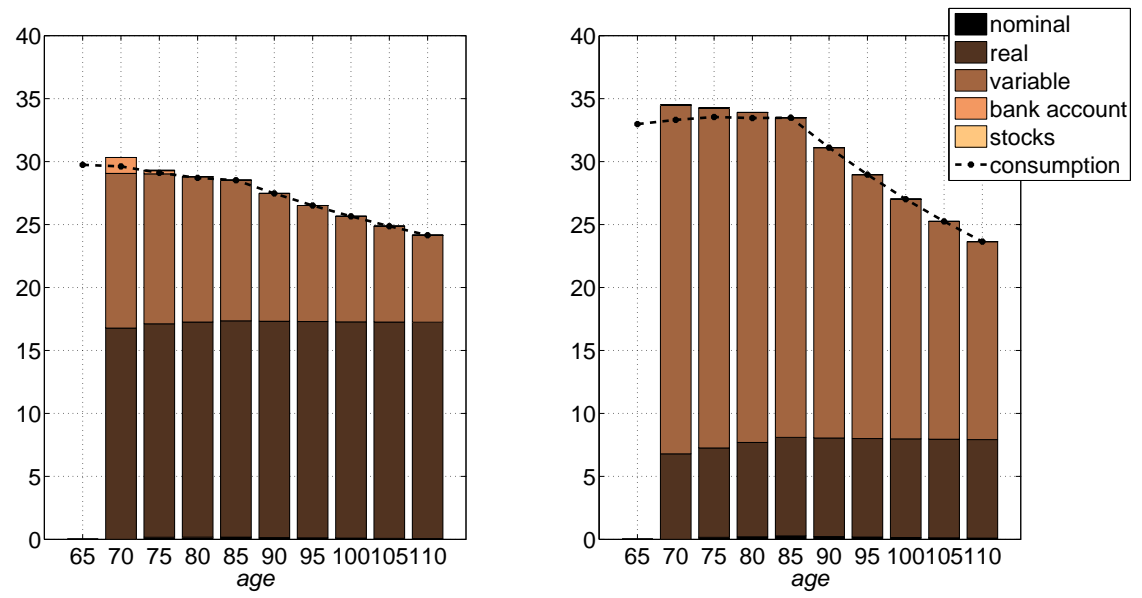

(a) Power utility maximization, $\rho=0.04, \gamma=-7$ (left) and $\gamma=-2$ (right).
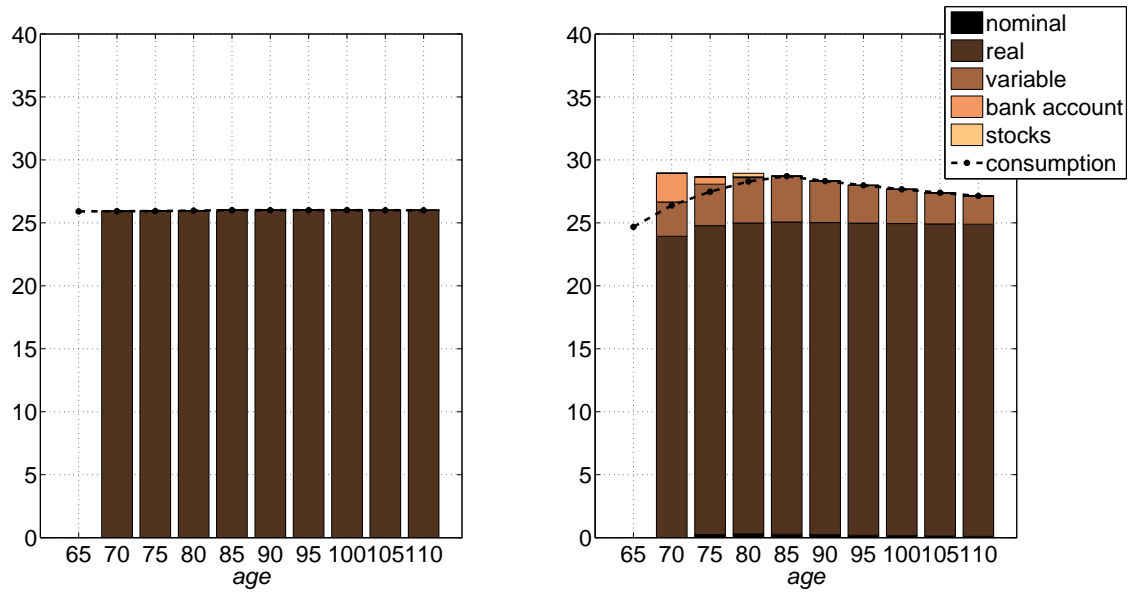

(b) Disutility minimization, $v=0.0, \widehat{C} \geq 25.9$ (left) and $\widehat{C} \geq 30$ (right).

Figure 5: Expected optimal consumption and retirement income in real terms (in £). Retirement income consists of the cash-flows from the annuities and the amount earned from selling cash and stocks.

( $\alpha_{t}^{a, j}$ is below $£ 2$ ), which indicates that the main investment and consumption decisions are made upon retirement. Afterwards the individual makes only small re-adjustments to the portfolio. Konicz et al. (2014b) show that when a retiree has access to immediate and deferred annuities, both with different maturities, he never consumes the entire cash-flows from annuities, but keeps a certain amount for rebalancing purposes. In addition, he invests in liquid assets (stocks and bonds) and explores time-varying investment opportunities more frequently when he has a bequest motive. In this study we consider only life long immediate annuities and no bequest motive, therefore we observe a different behaviour of a retiree.

Disutility minimization A second objective that we analyze is the minimization of the deviations from a target consumption $\widehat{C}_{t}$, which is adjusted to inflation. We allow the target to be a variable in the program, but to account for risk aversion we set a lower limit on this target. The higher the limit, the more aggressive the investment strategy, and the lower the risk aversion. In particular, we define the retiree to be risk averse when he chooses his target to be at least equal to the cash-flows from the real annuities, i.e. $\widehat{C}=25.9(£)$. A less risk averse retiree chooses any target higher than this amount. 


\begin{tabular}{|c|c|c|c|c|c|c|c|c|c|}
\hline \multirow{2}{*}{\multicolumn{2}{|c|}{ Power utility maximization }} & \multicolumn{4}{|c|}{$\gamma=-7$} & \multicolumn{4}{|c|}{$\gamma=-2$} \\
\hline & & 65 & 70 & 75 & 80 & 65 & 70 & 75 & 80 \\
\hline \multirow{5}{*}{ Asset allocation } & Nominal & 0 & 1 & 1 & 1 & 0 & 1 & 1 & 1 \\
\hline & Real & 68 & 69 & 70 & 70 & 29 & 31 & 33 & 34 \\
\hline & Variable & 30 & 30 & 29 & 29 & 71 & 69 & 66 & 65 \\
\hline & Cash & 2 & 0 & 0 & 0 & 0 & 0 & 0 & 0 \\
\hline & Stocks & 0 & 0 & 0 & 0 & 0 & 0 & 0 & 0 \\
\hline \multirow{2}{*}{ Consumption } & $\mathbb{E}\left[C_{t}\right]$ & 29.7 & 29.6 & 29.1 & 28.5 & 33.0 & 33.3 & 33.5 & 33.6 \\
\hline & $\sigma\left[C_{t}\right]$ & 0.0 & 4.0 & 6.1 & 9.7 & 0.0 & 9.0 & 13.6 & 21.4 \\
\hline \multirow{2}{*}{\multicolumn{2}{|c|}{ Disutility minimization }} & \multicolumn{4}{|c|}{$\widehat{C} \geq 25.9(£)$} & \multicolumn{4}{|c|}{$\widehat{C} \geq 30(£)$} \\
\hline & & 65 & $\overline{70}$ & 75 & 80 & 65 & $70^{-}$ & 75 & 80 \\
\hline \multirow{5}{*}{ Asset allocation } & Nominal & 0 & 0 & 0 & 0 & 0 & 1 & 1 & 1 \\
\hline & Real & 100 & 100 & 100 & 100 & 91 & 91 & 89 & 88 \\
\hline & Variable & 0 & 0 & 0 & 0 & 6 & 8 & 9 & 9 \\
\hline & Cash & 0 & 0 & 0 & 0 & 3 & 1 & 0 & 1 \\
\hline & Stocks & 0 & 0 & 0 & 0 & 0 & 0 & 1 & 0 \\
\hline \multirow{2}{*}{ Consumption } & $\mathbb{E}\left[C_{t}\right]$ & 25.9 & 25.9 & 25.9 & 25.9 & 24.7 & 26.4 & 27.4 & 28.6 \\
\hline & $\sigma\left[C_{t}\right]$ & 0.0 & 0.0 & 0.0 & 0.0 & 0.0 & 1.3 & 1.4 & 2.1 \\
\hline
\end{tabular}

Table 3: The expected optimal asset allocation (rounded to the nearest percent) and consumption (in $£$ ) under the power utility maximization with $\rho=0.04$ and the disutility minimization with $v=0$.

Figure $5 \mathrm{~b}$ shows that, similarly to the power utility maximization, the primary assets in the portfolio are the real and variable annuities. The optimal investment strategy for $\widehat{C} \geq 25.9$ (£) comprises $100 \%$ in real annuities, implying the optimal target level equal to the lower bound. Table 3 shows that the consumption is constant in real terms (has zero volatility), and the target is achieved at every single scenario. This result further shows that real annuities are the only products that give a perfect hedge against inflation, and investing only in inflation-linked annuities is a risk-free investment in real terms.

To investigate the optimal decisions for a less risk averse retiree, we increase the target consumption by choosing $\widehat{C} \geq 30(£)$. We observe that his investment strategy is more aggressive (he invests a small percentage of the portfolio (6-9\%) in variable annuities), and the resulting consumption is on average higher but also more volatile. The optimal solution is a trade-off between trying to reach the target and minimizing squared deviations from the target. Consequently, as reaching the higher target implies more aggressive investment strategy and more volatile consumption, the retiree consumes on average less than the target.

Similarly to the power utility maximization, the main investment decisions are made upon retirement. While the more risk averse retiree does not make any decisions at all during retirement, the less risk averse individual re-adjusts the portfolio by purchasing small amounts of all available assets. In particular, from Table 4 we read that upon age 70 and 75 , the retiree trades mainly stocks $\left(\alpha_{t}^{S, 0}=3.7(£)\right)$, and that he sells them whenever expecting low stock returns and a decrease in inflation, real and nominal returns. Comparing the consumption and investment decisions in the disutility minimization framework and in the power utility maximization framework, we find that the latter leads on average to much higher, though more volatile consumption (which is achieved by following a significantly more aggressive investment strategy).

No access to inflation-linked annuities The results from the considered optimization models clearly show that, independently of their risk aversion and objective function, retirees should invest in real 


\begin{tabular}{|c|c|c|c|c|c|c|c|}
\hline & \multirow{2}{*}{$\begin{array}{c}\text { Relative } \\
\text { Consumption (in \%) } \\
\end{array}$} & \multicolumn{5}{|c|}{ Purchase - Sale (in £) } \\
\hline & & & Nominal & Real & Variable & Cash & Stocks \\
\hline \multicolumn{8}{|c|}{ Power utility maximization, $\gamma=-7$} \\
\hline$t=t_{0}$ & $\alpha_{t}^{a, 0}$ & 30 & 0.0 & 47.9 & 21.1 & 1.2 & 0.0 \\
\hline \multirow{5}{*}{$t=t_{1}, t_{2}$} & Constant, $\alpha_{t}^{a, 0}$ & 99 & 0.8 & 1.1 & 0.0 & 0.0 & 0.5 \\
\hline & Stock returns, $\alpha_{t}^{a, 1}$ & 1 & 0.1 & -0.5 & 0.0 & 0.0 & -0.3 \\
\hline & Inflation, $\alpha_{t}^{a, 2}$ & 0 & -0.1 & -0.1 & 0.0 & 0.0 & 0.0 \\
\hline & Real returns $\alpha_{t}^{a, 3}$ & 0 & 0.2 & -0.1 & 0.0 & 0.0 & 0.0 \\
\hline & Nominal returns, $\alpha_{t}^{a, 4}$ & 0 & -0.4 & -0.2 & 0.0 & 0.0 & 0.1 \\
\hline \multicolumn{8}{|c|}{ Power utility maximization, $\gamma=-2$} \\
\hline$t=t_{0}$ & $\alpha_{t}^{a, 0}$ & 33 & 0.0 & 19.4 & 47.6 & 0.0 & 0.0 \\
\hline \multirow{5}{*}{$t=t_{1}, t_{2}$} & Constant, $\alpha_{t}^{a, 0}$ & 98 & 1.2 & 1.7 & 0.4 & 0.0 & 0.0 \\
\hline & Stock returns, $\alpha_{t}^{a, 1}$ & 2 & -0.4 & -1.5 & 0.5 & 0.0 & 0.0 \\
\hline & Inflation, $\alpha_{t}^{a, 2}$ & 0 & 0.3 & -0.2 & -0.1 & 0.0 & 0.0 \\
\hline & Real returns $\alpha_{t}^{a, 3}$ & 1 & 0.1 & -0.5 & 0.3 & 0.0 & 0.0 \\
\hline & Nominal returns, $\alpha_{t}^{a, 4}$ & 0 & -0.1 & -0.5 & 0.4 & 0.0 & 0.0 \\
\hline \multicolumn{8}{|c|}{ Disutility minimization, $\widehat{C} \geq 25.9(£)$} \\
\hline$t=t_{0}$ & $\alpha_{t}^{a, 0}$ & 26 & 0.0 & 74.1 & 0.0 & 0.0 & 0.0 \\
\hline \multirow{5}{*}{$t=t_{1}, t_{2}$} & Constant, $\alpha_{t}^{a, 0}$ & 100 & 0.0 & 0.0 & 0.0 & 0.0 & 0.0 \\
\hline & Stock returns, $\alpha_{t}^{a, 1}$ & 0 & 0.0 & 0.0 & 0.0 & 0.0 & 0.0 \\
\hline & Inflation, $\alpha_{t}^{a, 2}$ & 0 & 0.0 & 0.0 & 0.0 & 0.0 & 0.0 \\
\hline & Real returns $\alpha_{t}^{a, 3}$ & 0 & 0.0 & 0.0 & 0.0 & 0.0 & 0.0 \\
\hline & Nominal returns, $\alpha_{t}^{a, 4}$ & 0 & 0.0 & 0.0 & 0.0 & 0.0 & 0.0 \\
\hline \multicolumn{8}{|c|}{ Disutility minimization, $\widehat{C} \geq 30(£)$} \\
\hline$t=t_{0}$ & $\alpha_{t}^{a, 0}$ & 25 & 0.0 & 68.4 & 4.7 & 2.2 & 0.0 \\
\hline \multirow{5}{*}{$t=t_{1}, t_{2}$} & Constant, $\alpha_{t}^{a, 0}$ & 96 & 0.9 & 1.1 & 0.9 & 0.2 & 3.7 \\
\hline & Stock returns, $\alpha_{t}^{a, 1}$ & 1 & 0.5 & -0.1 & 0.1 & -0.2 & -1.4 \\
\hline & Inflation, $\alpha_{t}^{a, 2}$ & 0 & -0.4 & 0.0 & 0.1 & -0.1 & -0.9 \\
\hline & Real returns $\alpha_{t}^{a, 3}$ & 0 & 0.3 & 0.1 & 0.1 & 0.0 & -1.0 \\
\hline & Nominal returns, $\alpha_{t}^{a, 4}$ & 0 & 0.4 & 0.1 & 0.1 & -0.1 & -0.5 \\
\hline
\end{tabular}

Table 4: Regression coefficients indicating the conditional and unconditional optimal consumption relative to the retirement income (in \%) and conditional and unconditional optimal traded amount (in £, given that the individual trades at all).

annuities. Nevertheless, having in mind that 95\% of British retirees are reluctant to purchase inflationlinked annuities, we explore how they should optimally allocate their savings without investing in real annuities. In particular, we solve the same two optimization problems, but with variable $B u y_{t, n}^{R}$ set to zero.

Figures $6 \mathrm{a}$ and $6 \mathrm{~b}$ show the results for the individual who maximizes the expected utility of consumption, and who penalizes the deviations from the target, respectively, under the assumption of zero investment in inflation-linked annuities. We observe that the individual tries to hedge inflation risk by allocating his wealth primarily to variable and nominal annuities. The disutility minimizing individual invests furthermore a small amount of savings in stocks and cash (see also Table 5).

In most of the considered cases, retirees who decide not to allocate their savings to real annuities face lower retirement income. The only exception is the power utility maximizing individual with $\gamma=-2$, who achieves a higher expected consumption, though at the price of employing a more aggressive investment strategy (a 10\% higher allocation to variable annuities than if he invested in real annuities). Moreover, 

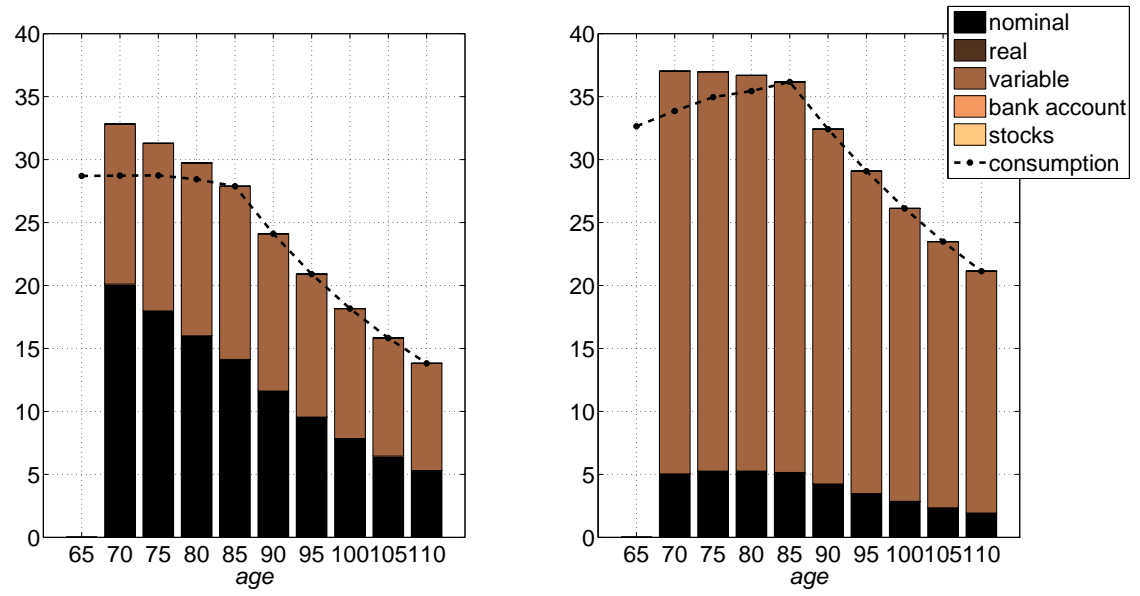

(a) Power utility maximization, $\rho=0.04, \gamma=-7$ (left) and $\gamma=-2$ (right).
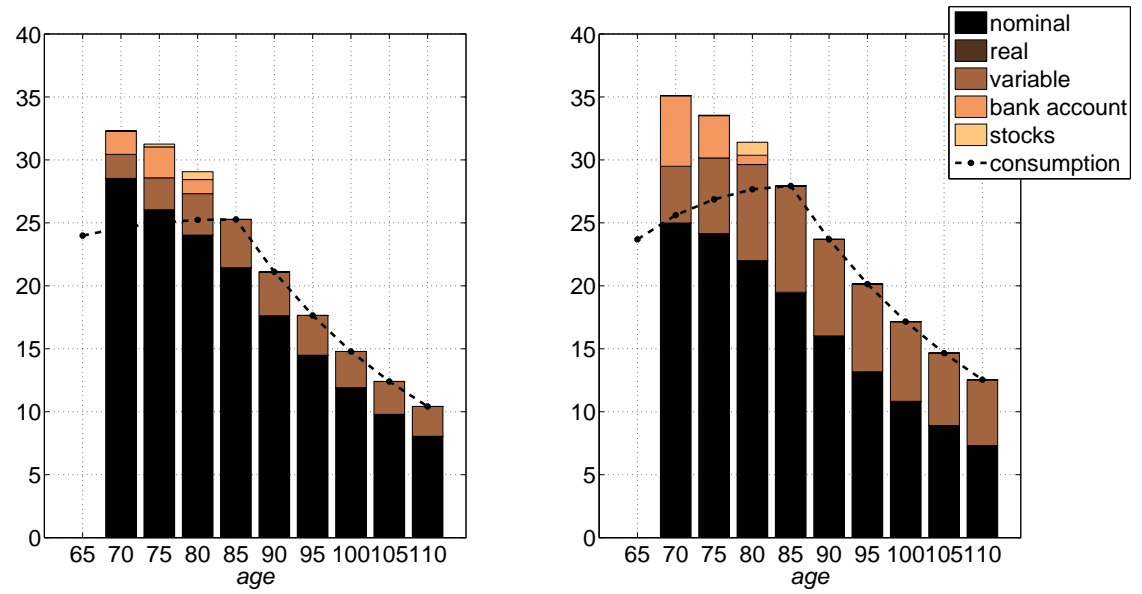

(b) Disutility minimization, $v=0.0, \widehat{C} \geq 25.9$ (left) and $\widehat{C} \geq 30$ (right).

Figure 6: Expected optimal consumption and retirement income in real terms (in £) without investment in real annuities. Retirement income consists of the cash-flows from the annuities and the amount earned from selling cash and stocks.

the lack of real annuities in the portfolio leads to more volatile retirement income.

The regression results on the relative consumption and on the traded amount, both presented in Table 6, show that the lack of investment in inflation-linked annuities requires more frequent rebalancing. Accordingly, to benefit from time-varying investment opportunities, the retiree has to sacrifice some of his consumption. To exemplify, the disutility minimizing retiree consumes $80 \%$ of his retirement income (in contrast to $100 \%$ for $\widehat{C} \geq 25.9(£)$ and $96 \%$ for $\widehat{C} \geq 30(£)$, if he invested in real annuities), and spends the residual amount on the purchase of nominal annuities, cash and stocks. Independently of risk aversion, he buys cash and sells the stocks when he expects high stock returns and an increase in real and nominal interest rates. Under such market conditions, he also consumes less, as his goal is to smooth the consumption by penalizing both positive and negative deviations from the target. This behaviour differs from the behaviour of the power utility maximizing retiree, who consumes more when expecting high stock returns and an increase in real returns. 


\begin{tabular}{|c|c|c|c|c|c|c|c|c|c|}
\hline \multirow{2}{*}{\multicolumn{2}{|c|}{ Power utility maximization }} & \multicolumn{4}{|c|}{$\gamma=-7$} & \multicolumn{4}{|c|}{$\gamma=-2$} \\
\hline & & 65 & 70 & 75 & 80 & 65 & 70 & 75 & 80 \\
\hline \multirow{5}{*}{ Asset allocation } & Nominal & 69 & 67 & 64 & 62 & 18 & 20 & 21 & 22 \\
\hline & Real & 0 & 0 & 0 & 0 & 0 & 0 & 0 & 0 \\
\hline & Variable & 31 & 33 & 36 & 38 & 82 & 80 & 79 & 78 \\
\hline & Cash & 0 & 0 & 0 & 0 & 0 & 0 & 0 & 0 \\
\hline & Stocks & 0 & 0 & 0 & 0 & 0 & 0 & 0 & 0 \\
\hline \multirow{2}{*}{ Consumption } & $\mathbb{E}\left[C_{t}\right]$ & 28.7 & 28.7 & 28.8 & 28.0 & 32.6 & 33.9 & 35.0 & 36.2 \\
\hline & $\sigma\left[C_{t}\right]$ & 0.0 & 3.8 & 6.1 & 11.2 & 0.0 & 10.2 & 15.8 & 25.3 \\
\hline \multirow{2}{*}{\multicolumn{2}{|c|}{ Disutility minimization }} & \multicolumn{4}{|c|}{$\widehat{C} \geq 25.9(£)$} & \multicolumn{4}{|c|}{$\widehat{C} \geq 30(£)$} \\
\hline & & 65 & $7 \overline{0}$ & 75 & 80 & 65 & 70 & 75 & 80 \\
\hline \multirow{5}{*}{ Asset allocation } & Nominal & 92 & 89 & 86 & 82 & 81 & 81 & 77 & 72 \\
\hline & Real & 0 & 0 & 0 & 0 & 0 & 0 & 0 & 0 \\
\hline & Variable & 4 & 6 & 8 & 10 & 10 & 14 & 18 & 21 \\
\hline & Cash & 3 & 4 & 4 & 6 & 9 & 5 & 2 & 5 \\
\hline & Stocks & 0 & 1 & 2 & 3 & 0 & 0 & 3 & 2 \\
\hline \multirow{2}{*}{ Consumption } & $\mathbb{E}\left[C_{t}\right]$ & 24.0 & 24.6 & 25.0 & 25.2 & 23.7 & 25.6 & 26.9 & 27.9 \\
\hline & $\sigma\left[C_{t}\right]$ & 0.0 & 0.8 & 0.9 & 1.9 & 0.0 & 2.1 & 2.3 & 4.1 \\
\hline
\end{tabular}

Table 5: The expected optimal asset allocation (rounded to the nearest percent) and consumption (in $£$ ) under the power utility maximization with $\rho=0.04$ and the disutility minimization with $v=0$, and given no investment in real annuities.

\section{Conclusions and future work}

This paper studies optimal consumption and investment decisions for an uncertain lived retiree facing inflation risk. Having access to nominal, real, and variable annuities, as well as a bank account and stocks, the individual optimizes his decisions under two different objectives: 1) maximization of the power utility of real consumption, and 2) minimization of the squared deviations from the target that increases with inflation.

Our findings show that independently of the considered objective function and risk aversion, the optimal asset allocation comprises real annuities. The second crucial asset in the portfolio are variable annuities, and their weight increases with the risk tolerance. Our results are thus consistent with the literature investigating the demand on the inflation-linked products - they are beneficial for individuals. Furthermore, the results indicate that the most important decisions are made upon retirement, and even though the individual is allowed to rebalance the portfolio, he makes only small re-adjustments during the retirement period. In addition, we find that the allocation to nominal annuities, cash, and stocks, is marginal, unless the retiree chooses not to invest in real annuities at all. In such a case, he tries to hedge his portfolio against inflation by purchasing primarily nominal and variable annuities. Consequently, the real consumption is more volatile than if he invested in real annuities, and in most of the cases lower. The lack of real annuities in the portfolio also requires more frequent rebalancing, leading to an investment strategy that may be too complicated for many retirees.

The model could be improved in multiple ways. Some straightforward extensions include adding a bequest motive, additional contributions, and/or other annuities such as joint life or nominal annuities with different payouts. Among more advanced improvements, an inclusion of other inflation-linked products, e.g. those offering a deflation floor to the initial cash-flow, would definitely be worth to investigate. 


\begin{tabular}{|c|c|c|c|c|c|c|}
\hline & \multirow{2}{*}{$\begin{array}{c}\text { Relative } \\
\text { Consumption (in \%) }\end{array}$} & \multicolumn{4}{|c|}{ Purchase - Sale (in £) } \\
\hline & & & Nominal & Variable & Cash & Stocks \\
\hline \multicolumn{7}{|c|}{ Power utility maximization, $\gamma=-7$} \\
\hline$t=t_{0}$ & $\alpha_{t}^{a, 0}$ & 29 & 49.5 & 21.8 & 0.0 & 0.0 \\
\hline \multirow{5}{*}{$t=t_{1}, t_{2}$} & Constant, $\alpha_{t}^{a, 0}$ & 92 & 2.8 & 0.0 & 1.8 & 0.0 \\
\hline & Stock returns, $\alpha_{t}^{a, 1}$ & 1 & -0.5 & 0.0 & 0.7 & 0.0 \\
\hline & Inflation, $\alpha_{t}^{a, 2}$ & 0 & -0.1 & 0.0 & -0.1 & 0.0 \\
\hline & Real returns $\alpha_{t}^{a, 3}$ & 1 & 0.1 & 0.0 & 0.6 & 0.0 \\
\hline & Nominal returns, $\alpha_{t}^{a, 4}$ & 0 & 0.0 & 0.0 & 0.6 & 0.0 \\
\hline \multicolumn{7}{|c|}{ Power utility maximization, $\gamma=-2$} \\
\hline$t=t_{0}$ & $\alpha_{t}^{a, 0}$ & 33 & 12.4 & 54.9 & 0.0 & 0.0 \\
\hline \multirow{5}{*}{$t=t_{1}, t_{2}$} & Constant, $\alpha_{t}^{a, 0}$ & 94 & 2.8 & 0.0 & 1.5 & 0.0 \\
\hline & Stock returns, $\alpha_{t}^{a, 1}$ & 4 & -1.4 & 0.0 & -0.2 & 0.0 \\
\hline & Inflation, $\alpha_{t}^{a, 2}$ & 0 & -0.1 & 0.0 & 0.0 & 0.0 \\
\hline & Real returns $\alpha_{t}^{a, 3}$ & 0 & -0.3 & 0.0 & 0.2 & 0.0 \\
\hline & Nominal returns, $\alpha_{t}^{a, 4}$ & 0 & -0.1 & 0.0 & 0.3 & 0.0 \\
\hline \multicolumn{7}{|c|}{ Disutility minimization, $\widehat{C} \geq 25.9(£)$} \\
\hline$t=t_{0}$ & $\alpha_{t}^{a}$ & 24 & 70.2 & 3.3 & 2.6 & 0.0 \\
\hline \multirow{5}{*}{$t=t_{1}, t_{2}$} & Constant, $\alpha_{t}^{a, 0}$ & 80 & 4.6 & 0.0 & 2.1 & 3.3 \\
\hline & Stock returns, $\alpha_{t}^{a, 1}$ & 1 & 0.2 & 0.0 & 1.7 & -1.5 \\
\hline & Inflation, $\alpha_{t}^{a, 2}$ & 0 & -0.4 & 0.0 & -0.2 & 0.6 \\
\hline & Real returns $\alpha_{t}^{a, 3}$ & -2 & 0.8 & 0.0 & 0.6 & -1.0 \\
\hline & Nominal returns, $\alpha_{t}^{a, 4}$ & -1 & 0.2 & 0.0 & 1.4 & -0.9 \\
\hline \multicolumn{7}{|c|}{ Disutility minimization, $\widehat{C} \geq 30(£)$} \\
\hline$t=t_{0}$ & $\alpha_{t}^{a, 0}$ & 24 & 61.5 & 7.7 & 7.1 & 0.0 \\
\hline \multirow{5}{*}{$t=t_{1}, t_{2}$} & Constant, $\alpha_{t}^{a, 0}$ & 81 & 5.0 & 0.0 & 3.9 & 3.6 \\
\hline & Stock returns, $\alpha_{t}^{a, 1}$ & -1 & -0.2 & 0.0 & 1.7 & -1.9 \\
\hline & Inflation, $\alpha_{t}^{a, 2}$ & 1 & 0 & 0.0 & -0.1 & 0.0 \\
\hline & Real returns $\alpha_{t}^{a, 3}$ & -2 & 0.2 & 0.0 & 0.9 & -1.2 \\
\hline & Nominal returns, $\alpha_{t}^{a, 4}$ & -1 & 0.5 & 0.0 & 1.4 & -0.7 \\
\hline
\end{tabular}

Table 6: Regression coefficients indicating the conditional and unconditional optimal consumption relative to the retirement income (in \%) and conditional and unconditional optimal traded amount (in £, given that the individual trades at all), given no investment in inflation-linked annuities.

\section{References}

Attié, A. P. and Roache, S. K. (2009). Inflation hedging for long term investors. Technical report, International Monetary Fund.

Barberis, N. C. (2000). Investing for the long run when returns are predictable. The Journal of Finance, $55: 225-264$.

Birge, J. R. and Louveaux, F. (1997). Introduction to Stochastic Programming. Springer Series in Operations Research and Financial Engineering. Springer, corrected edition.

Blake, D., Wright, D., and Zhang, Y. (2013). Target-driven investing: Optimal investment strategies in defined contribution pension plans under loss aversion. Journal of Economic Dynamics and Control, 37(1):195-209.

Brennan, M. and Xia, Y. (2002). Dynamic asset allocation under inflation. Journal of Finance, 57(3):1201-1238. 
Brown, J. R., Mitchell, O. S., and Poterba, J. M. (2000). Mortality risk, inflation risk, and annuity products. NBER Working Papers 7812, National Bureau of Economic Research, Inc.

Brown, J. R., Mitchell, O. S., and Poterba, J. M. (2001). The role of real annuities and indexed bonds in an individual accounts retirement program. Risk aspects of investment-based social security reform, pages $321-369$.

Cairns, A. (2000). Some notes on the dynamics and optimal control of stochastic pension fund models in continuous time. ASTIN Bulletin, 30(1):19-55.

Campbell, J. Y., Chan, Y. L., and Viceira, L. M. (2003). A multivariate model of strategic asset allocation. Journal of Financial Economics, 67:41-80.

Campbell, J. Y. and Viceira, L. M. (2001). Who should buy long-term bonds? American Economic Review, 91(1):99-127.

Carino, D. R. and Ziemba, W. T. (1998). Formulation of the Russell-Yasuda Kasai financial planning model. Operations Research, 46(4):433-449.

Christensen, J. H. E., Lopez, J. A., and Rudebusch, G. D. (2010). Inflation expectations and risk premiums in an arbitrage-free model of nominal and real bond yields. Journal of Money, Credit and Banking, 42:143-178.

Cowie, A. (2011). 95pc of private sector pensions have no inflation protection at all. The Telegraph, http://blogs.telegraph.co.uk/finance/ianmcowie/100012810/ 95pc-of-private-sector-pensions-have-no-inflation-protection-at-all/

Dellinger, J. K. (2006). The Handbook of Variable Income Annuities. Hoboken, NJ : Wiley.

Di Giacinto, M., Federico, S., Gozzi, F., and Vigna, E. (2014). Income drawdown option with minimum guarantee. European Journal of Operational Research, 234(3):610-624.

Diebold, F. X. and Li, C. (2006). Forecasting the term structure of government bond yields. Journal of Econometrics, 130:337-364.

Fama, E. (1981). Stock returns, real activity, inflation, and money. American Economic Review, $71(4): 545-565$.

Ferstl, R. and Weissensteiner, A. (2011). Asset-liability management under time-varying investment opportunities. Journal of Banking \& Finance, 35(1):182 - 192.

Fischer, S. (1975). The demand for index bonds. Journal of Political Economy, 83(3):509.

Gerrard, R., Haberman, S., and Vigna, E. (2004). Optimal investment choices post-retirement in a defined contribution pension scheme. Insurance: Mathematics and Economics, 35(2):321-342.

Geske, R. and Roll, R. (1983). The fiscal and monetary linkage between stock returns and inflation. Journal of Finance, 38(1):1-33.

Geyer, A., Hanke, M., and Weissensteiner, A. (2012). Inflation forecasts extracted from nominal and real yield curves. Working paper. Available at: http://papers.ssrn.com/sol3/papers.cfm?abstract_ id=1727068.

Gilli, M., Große, S., and Schumann, E. (2010). Calibrating the Nelson-Siegel-Svensson model. COMISEF Working Paper Series, pages 1-23.

Han, N. and Hung, M. (2012). Optimal asset allocation for DC pension plans under inflation. Insurance: Mathematics and Economics, 51(1):172-181.

Høyland, K., Kaut, M., and Wallace, S. W. (2003). A heuristic for moment-matching scenario generation. Computational Optimization and Applications, 24(2-3):169-185.

Høyland, K. and Wallace, S. W. (2001). Generating scenario trees for multistage decision problems. Management Science, 47(2):295-307. 
Hyde, D. (2013). The inflation-linked pensions that don’t pay off until you're 97, leaving retirees $£ 20,000$ out of pocket. Time is Money, http://www.thisismoney.co.uk/money/pensions/article-2281283/ The-inflation-linked-pensions-dont-pay-youre-97-leaving-retirees-20-000-pocket.html

Joyce, M., Lildholdt, P. M., and Sorensen, S. (2010). Extracting inflation expectations and inflation risk premia from the term structure: A joint model of the UK nominal and real yield curves. Journal of Banking and Finance, 34(2):281-294.

Koijen, R. S. J., Nijman, T. E., and Werker, B. J. M. (2011). Optimal annuity risk management. Review of Finance, 15(4):799-833.

Konicz, A. K., Pisinger, D., Rasmussen, K. M., and Steffensen, M. (2014a). A combined stochastic programming and optimal control approach to personal finance and pensions. OR Spectrum.

Konicz, A. K., Pisinger, D., and Weissensteiner, A. (2014b). Optimal retirement planning with a focus on single and multilife annuities. Technical report, DTU Management Engineering.

Kwak, M. and Lim, B. H. (2014). Optimal portfolio selection with life insurance under inflation risk. Journal of Banking and Finance, 46:59-71.

Lee, B. (1992). Causal relations among stock returns, interest-rates, real activity, and inflation. Journal of Finance, 47(4):1591-1603.

Lütkepohl, H. (2005). Introduction to Multiple Time Series Analysis. Springer.

Milevsky and Young (2007). Annuitization and asset allocation. Journal of Economic Dynamics and Control, 31(9):3138-3177.

Mulvey, J. M., Simsek, K. D., Zhang, Z., Fabozzi, F. J., and Pauling, W. R. (2008). Assisting definedbenefit pension plans. Operations Research, 56(5):1066-1078.

Nelson, C. R. and Siegel, A. F. (1987). Parsimonious modeling of yield curves. Journal of Business, 60:473-489.

Pedersen, A. M. B., Weissensteiner, A., and Poulsen, R. (2013). Financial planning for young households. Annals of Operations Research, 205(1):55-76.

Soares, C. and Warshawsky, M. (2003). Research paper no. 2003-01 annuity risk: Volatility and inflation exposure in payments from immediate life annuities.

Towler, J. (2013). A hard sell: The problem with inflation-linked annuities. IFAonline, http://www.ifaonline.co.uk/ifaonline/feature/2301326/ a-hard-sell-the-problem-with-inflation-linked-annuities

Yaari, M. E. (1965). Uncertain lifetime, life insurance, and the theory of the consumer. The Review of Economic Studies, 32(2):137-150.

Zenios, S. (2008). Practical Financial Optimization: Decision Making for Financial Engineers. Wiley. 
The paper investigates the importance of inflation-linked annuities to individuals facing inflation risk. Given the investment opportunities in nominal, real, and variable annuities, as well as cash and stocks, we investigate the consumption and investment decisions under two different objective functions: 1) maximization of the expected CRRA utility function, and 2) minimization of squared deviations from an inflationadjusted target. To find the optimal decisions we apply a multi-stage stochastic programming approach. Our findings indicate that independently of the considered objective function and risk aversion, real annuities are a crucial asset in every portfolio. In addition, without investing in real annuities, the retiree has to rebalance the portfolio more frequently, and still obtains the lower and more volatile real consumption. 